\title{
ADJUSTING SOCIAL SECURITY FOR INCREASING LIFE EXPECTANCY: EFFECTS ON PROGRESSIVITY
}

\author{
Courtney Monk, John A. Turner, and Natalia A. Zhivan
}

CRR WP 2010-9

Date Submitted: July 2010

Date Released: August 2010

\author{
Center for Retirement Research at Boston College \\ Hovey House \\ 140 Commonwealth Avenue \\ Chestnut Hill, MA 02467 \\ Tel: 617-552-1762 Fax: 617-552-0191 \\ http://crr.bc.edu
}

Courtney Monk currently works for Teach for America and is a former senior economist at the Center for Retirement Research at Boston College (CRR). John A. Turner is director of the Pension Policy Center. Natalia A. Zhivan currently is an adjunct instructor at Tulane University and is a former consultant for the CRR. The research reported here was performed pursuant to a grant from the U.S. Social Security Administration funded as part of the Retirement Research Consortium. The opinions and conclusions expressed are solely those of the authors and do not represent the opinions or policy of the U.S. Social Security Administration, any agency of the Federal Government, the Pension Policy Center, or the Center for Retirement Research at Boston College.

(C) 2010, by Courtney Monk, John A. Turner, and Natalia A. Zhivan. All rights reserved. Short sections of text, not to exceed two paragraphs, may be quoted without explicit permission provided that full credit, including (C) notice, is given to the source. 


\title{
About the Center for Retirement Research
}

The Center for Retirement Research at Boston College, part of a consortium that includes parallel centers at the University of Michigan and the National Bureau of Economic Research, was established in 1998 through a grant from the Social Security Administration. The Center's mission is to produce first-class research and forge a strong link between the academic community and decision makers in the public and private sectors around an issue of critical importance to the nation's future. To achieve this mission, the Center sponsors a wide variety of research projects, transmits new findings to a broad audience, trains new scholars, and broadens access to valuable data sources.

\author{
Center for Retirement Research at Boston College \\ Hovey House \\ 140 Commonwealth Avenue \\ Chestnut Hill, MA 02467 \\ phone: 617-552-1762 fax: 617-552-0191 \\ e-mail: crr@bc.edu \\ crr.bc.edu
}

Affiliated Institutions:

The Brookings Institution

Massachusetts Institute of Technology

Syracuse University

Urban Institute 


\begin{abstract}
Achieving long-run Social Security solvency requires addressing rising life expectancy. Increasing the Full Retirement Age (FRA), while holding the Early Entitlement Age (EEA) fixed, could be effective but eventually will result in replacement rates that are viewed by many as too low. A possible policy to prop up replacement rates is to raise the EEA, which has been age 62 for more than 40 years. However, an increase in the EEA introduces unfairness because the variation in life expectancy across socioeconomic groups is positively correlated with lifetime income. Using data from the Health and Retirement Study to investigate how earnings relate to mortality risk and health limitations, this project explores the possibility of constructing a flexible FRA that could preserve or even enhance the progressivity of Social Security benefits. If life expectancy were correlated with lifetime income, Social Security policy could use the AIME (Average Indexed Monthly Earnings) to target policies that are more equitable for people with both lower lifetime income and lower life expectancy. Unfortunately, we find that while life expectancy is strongly correlated with AIME for men, it is only weakly correlated for women, and when pooling the genders the correlation disappears. We then investigate whether targeting could be done by the max AIME, which is the AIME for single persons and the maximum of the husband's or wife's AIME for married couples. We find that the max AIME, which is a household measure of lifetime income, could be used for constructing a flexible FRA because it is negatively correlated with mortality risk and also negatively correlated with other measures of economic vulnerability or inability to work at older ages. With a flexible FRA, individuals in households with a low max AIME would have a lower FRA than other individuals.
\end{abstract}




\section{Introduction}

Restoring long-term solvency to Social Security is the most important aspect of retirement benefit reform. Although several factors are at play, Social Security's actuarial deficit arises in part because life expectancy continues to increase (Table 1). As a result, a 65-year-old in 1935 and a 75 -year-old in 2008 had about the same number of expected remaining years of life (Shoven and Goda 2008). Even if Social Security had no actuarial deficit today based on current life expectancy, it would still be necessary to address rising life expectancy in order to maintain solvency going forward. ${ }^{1}$

In considering policy options to address rising longevity, it is important to consider their effects on the progressivity of Social Security. Some commonly considered policy options to restore solvency to Social Security may be unfair to people with low life expectancy. In particular, policies that cut benefits as the way to deal with increasing life expectancy cause the replacement rate to decline over time. The replacement rate in Social Security is not generous by international standards. Further declines may eventually cause it to fall to a level that is viewed by many people as being inadequate, particularly for people with low incomes who depend largely on Social Security benefits.

A possible mechanism to offset the benefit cuts caused by a rising Full Retirement Age (FRA), which is set in law to increase from age 66 to 67 , is to raise the Early Entitlement Age (EEA), which has been age 62 for more than 40 years. However, an

\footnotetext{
${ }^{1}$ We note that the assumption that life expectancy will continue to rise as medical advancements are made underpins much of the reasoning behind the need to adjust Social Security for longevity. This assumption is a sound one, as life expectancy does not seem to be approaching its limit as of yet (Oeppen and Vaupel 2002). We do note that some research argues that the rising prevalence of obesity will offset many of these gains (see, for example, Olshansky et al. 2005). However, we take this as further evidence that a flexible form of longevity indexing is important, since obesity is also linked to low socioeconomic status (though this link may be weaker now than it has been in recent decades (Zhang and Wang 2004)).
} 
increase in the EEA has a larger adverse effect on people with lower life expectancy due to their shorter number of expected years remaining. In addition, raising the EEA hurts people with poor job prospects due to poor health or low skills, who have to rely on Social Security benefits as the only source of income.

This paper focuses on the effects of Social Security benefit cuts on people with low life expectancy, and attempts to develop a policy option that could protect replacement rates for people in households with both low income and high mortality. While people with low lifetime incomes clearly are a policy concern for Social Security, low family income tends to be correlated with low life expectancy, so that those people are doubly disadvantaged. Considerations of equity may include concern over both low annual Social Security benefits and low lifetime benefits, due in part to low life expectancy.

To the extent that life expectancy is correlated with lifetime income, Social Security could use the AIME (Average Indexed Monthly Earnings) to target policies. In this way, policies could be developed that are more equitable for people with both low lifetime income and low life expectancy.

We find that while life expectancy is strongly correlated with individual AIME for men, it is only weakly correlated for women, and when pooling the genders the correlation disappears. We then investigate whether targeting could be better done using a household measure of lifetime income, rather than an individual measure. The household measure we use is the max AIME, which is the AIME for single persons and the maximum of the husband's or wife's AIME for married couples. We find that the max AIME could be used for constructing a flexible FRA because it is negatively correlated with mortality risk and also negatively correlated with other measures of economic vulnerability or inability to 
work at older ages. This approach is, by construction, well targeted to households with low lifetime income. We also find, however, that it is well targeted to households where people have relatively low life expectancy. With a flexible FRA, individuals in households with lower lifetime incomes would have a lower FRA than other individuals. While everyone could still claim benefits at the EEA, that stays at age 62, the actuarial reduction for taking benefits at that age would be lower for people with lower lifetime income due to their having a lower FRA.

In addition to preserving replacement rates for this vulnerable population and addressing the equity concern for people with low life expectancies, an advantage of this approach - introducing flexible FRA with the EEA staying at age 62 - is that it maintains the availability of benefits at age 62 . Preserving the option to retire at that age and claim benefits protects people who are unable to work past age 62 , either due to poor health or poor labor market options and with no financial recourses to support an adequate standard of living in the absence of Social Security benefits. A disadvantage is that some people may choose to retire at age 62 because of the availability of benefits and their myopia as to the advantages of postponing retirement, when their long run interests would be better served by postponing retirement and receiving higher Social Security benefits. However, only people with relatively long life expectancies would benefit from postponing the claiming decision. Since in this case, their FRA will be set at a higher level, a much lower replacement rate at the EEA may discourage them from doing so.

The paper is structured as follows. It begins by examining how the effects of some Social Security reform options differ depending on differences in life expectancy across demographic groups. Section two discusses issues relating to Social Security progressivity 
and life expectancy. Section three uses data from the Health and Retirement Study to explore the correlation between AIME and life expectancy. While the correlations between life expectancy and education, current income, and financial wealth have been explored in other studies, we are unaware of previous studies examining the correlation with the AIME. AIME is information that the Social Security Administration could use to construct policies that differentiate between people with different lifetime income and life expectancy. The correlation between AIME and disability is also explored. Section four offers a robustness check for the AIME model by comparing it to one with demographic characteristics as explanatory variables. Section five presents a proposal for a flexible Full Retirement Age (FRA) based on differences in AIME. If AIME is correlated with life expectancy, a flexible FRA with a constant EEA could mitigate the dual problems of low replacement rates at the EEA and disparate effects of policy changes on people with both low lifetime income and low life expectancy. We find that AIME is not correlated with life expectancy when pooling men and women, but that a household measure of AIME, the max AIME, is correlated. Section six discusses implications of a flexible FRA based on max AIME. Individuals in households with a low max AIME would have a lower FRA than other individuals. A final section concludes. 


\section{Benefit Cuts to Restore Solvency while Maintaining An Acceptable Replacement Rate and Progressivity}

Many policy options could deal with the effects of increasing life expectancy on Social Security financing. ${ }^{2}$ First, the Full Retirement Age (FRA) could be raised to a higher predetermined age, as in the 1983 Amendments when the FRA was increased from 65 to 67 , with that change taking full effect for people born in 1960 or later. Liebman, MacGuineas, and Samwick (2005) suggest, for example, that the FRA be raised to 68. Second, the FRA could be indexed to rise as the life expectancy of people at retirement age increases. The 1994-1996 Advisory Council on Social Security included such a measure in its recommendations. ${ }^{3}$ Third, the FRA could remain fixed, with benefits indexed to life expectancy, so that benefits gradually decline as longevity rises for successive cohorts (Diamond and Orszag 2004). Other options include raising the payroll tax rate, raising the payroll tax ceiling, adding general revenue funding, and changing the benefit formula bend points.

Many of these policy options reduce Social Security replacement rates and would push some low-income people relying on Social Security into poverty. If in 2008 , for example, the FRA were at age 65, Social Security benefits for a low earner would replace 84 percent of poverty line income if claimed at 62 (Table 2). Average earners would be 40 percent above the poverty threshold, while high earners would receive approximately 80 percent more that the poverty line if they claim benefits at age 62 . If the FRA were to be set at age 67 , Social Security would replace only 73 percent of the poverty line income if

\footnotetext{
${ }^{2}$ See Social Security Advisory Board (2005) for a discussion of various additional options. In addition, see Turner (2008) for an international comparison of longevity-related reforms to Social Security systems.

${ }^{3}$ The Advisory Council's report is available at http://www.ssa.gov/history/reports/adcouncil/ report/toc.htm. The American Academy of Actuaries also advocates indexing the FRA to longevity.
} 
claimed at age 62. Average and high earners would receive benefits only slightly higher than the poverty threshold. Further increases in the FRA would push the benefits of low earners even further below the poverty line.

One option to offset benefit cuts due to a rise in the FRA is to raise the EEA. Raising the EEA from 62 to 63 would raise the annual benefits of those claiming before age 63 due to the actuarial adjustment, and could further raise their benefits if they worked the additional year. People already claiming Social Security benefits at age 63 or later would be unaffected. The effect on Social Security solvency of raising the EEA would be negligible because on average, across the population, doing it this way does not affect the expected lifetime level of benefits of retirees. However, raising the EEA would adversely affect individuals who currently claim at age 62 due to poor health or poor labor market opportunities and lack financial resources as they rely on Social Security retirement benefit as the only source of income at this age (Zhivan et al. 2008).

Figures 1 and 2 show the effect of raising the EEA on individuals with different life expectancies (for couples, refer to Figure A1 in the Appendix). In particular, Figure 1 shows the lifetime expected value of benefits at different ages of first receipt relative to the lifetime expected value of benefits claimed at age 62 for groups of people with different life expectancies. ${ }^{4}$ Figure 2 shows the ratio of lifetime expected value of benefits for groups with different life expectancies relative to a lifetime expected value of benefits for hypothetical individuals with a unisex life expectancy (an average of male and female life expectancies). The adjustment for postponed retirement between ages 62 and 66 is roughly

\footnotetext{
${ }^{4}$ An alternative measure would be the expected utility value of these benefits; however, that measure is not attempted because it would be affected by the level of risk aversion of different demographic groups. We do not have good information on how that varies, though some information indicates that women tend to be more risk averse than men.
} 
actuarially fair on average. According to Figure 2A, on average a black male with less than a high school degree receives almost 20 percent less over his lifetime relative to a hypothetical individual with unisex mortality; however, this difference will increase if he has to claim at later ages. Both Figures 1 and 2 show that for people with relatively high life expectancy, such as white females, moving the EEA from 62 to 63 or higher raises the lifetime expected value of benefits for those previously claiming benefits at an earlier age. By contrast, for people with relatively low life expectancy, such as black males, the opposite effect is found.

The effect of differences in life expectancy on policy outcomes is important because the disparities in life expectancy across groups can be large. When groups are broken into detailed categories by race, gender, and geographical area, the gap between the highest and lowest life expectancies for race-county combinations in the United States is over 35 years (Murray et al. 2006).

Furthermore, these differences have increased in recent decades, suggesting that in the future they may be even greater than today (Meara, Richards and Cutler 2008; Schoeni et al. 2005; Crimmins and Saito 2001; Freedman et al. 2004; Goesling 2007; Waldron 2007; Munnell, Soto, and Golub-Sass 2008). ${ }^{5}$ Table 1, for example, shows a pattern of growing disparities in life expectancy between whites and blacks. In 1950, black and white males age 65 had basically the same life expectancy, but by 2003, white males at 65 had a life expectancy two years longer than blacks.

The growing disparity in life expectancy by income has been even greater than by race. Males aged 60 in 1972 who were in the top half of the income distribution had a life

\footnotetext{
${ }^{5}$ Healthy life expectancy, which combines morbidity and mortality, is an indicator of expected years of life lived in full health without disease or disability.
} 
expectancy 1.2 years longer than those in the bottom half. By 2001, the difference had grown by 5.8 years (Waldron 2007).

In summary, benefit cuts to offset the effect of increasing life expectancy may eventually lead to a replacement rate that is so low as to be socially unacceptable. One way to address unduly low replacement rates is to raise the EEA. However, raising the EEA would adversely affect people with low life expectancy, and the extent of the adverse effect has increased over time due to the growing dispersion in life expectancy between income groups. Also, raising the EEA will eliminate the only source of income for some individuals who cannot work due to poor health or poor job prospects and lack financial recourses at age 62. Therefore, we seek a cost-cutting policy that accomplishes several goals: 1) keeps replacement rates acceptable while maintaining an EEA of 62; 2) addresses differences in life expectancy; and 3) adjusts for rising life expectancy.

\section{Progressivity and the Link Between AIME and Life Expectancy}

One important goal of Social Security is to reduce poverty in old age (Cohen et al. 2001). The benefit formula awards higher annual benefits, as a portion of lifetime earnings (and thus a higher replacement rate), to individuals with low earnings. The benefit formula, which produces the individual's primary insurance amount (PIA), is a nonlinear function. In 2009 , it was the sum of 90 percent of the first $\$ 744$ of AIME plus 32 percent of the amount between $\$ 744$ and $\$ 4,483$ plus 15 percent of any remaining amount above $\$ 4,483$.

Studies have shown that much of the desired redistribution from rich to poor households is mitigated by the design of the benefits. This outcome occurs because much of the individual redistribution occurs within households rather than between households 
(Gustman and Steinmeier 2001). At the level of the household, Social Security benefits represent a transfer from people with high earnings to their spouses with low earnings. This pattern is further accentuated by spousal and survivor benefits, which are higher for couples with a large gap in earnings, i.e. those with one high-earning and one low-earning spouse.

The progressivity of Social Security benefits is offset by other factors as well.

Specifically, because benefits are paid out until death as an annuity, Social Security transfers income from people with low life expectancy to those with high life expectancy (Liebman 2002). This feature undermines the progressivity of the program because highincome individuals tend to have high life expectancy (Brown 2003). Cohen et al. (2001) show that for men in particular, low mortality counteracts a large portion of the progressive benefit formula for lower income groups. Altogether, a large literature finds little actual redistribution of income by Social Security benefits (Gustman and Steinmeier 2001; Liebman 2002; Coronado et al. 2000; and Brown et al. 2009).

A substantial literature investigates the link between income and life expectancy (see Waldron 2007). In this paper, we take a slightly different approach and focus on whether AIME is a good predictor of life expectancy. Because AIME and quarters of covered work are data that SSA can access, these are the exact levers with which SSA could develop a framework for a flexible FRA. A flexible FRA that varied by AIME would target people with low lifetime income, but it could potentially also target people with low life expectancy. We address those issues in the next section.

\section{Empirical Relationships Between AIME, Life Expectancy, and Economic Vulnerability at Older Ages}


Because Social Security does not have administrative data on health or education of beneficiaries, a meaningful and useful adjustment mechanism for establishing a flexible FRA must be a function of AIME and/or quarters of covered earnings, both of which SSA does observe. This section, therefore, focuses on two relationships: 1) the link between AIME and life expectancy; and 2) the link between AIME and economic vulnerability (low wealth, disability, poor job opportunities, etc.).

To learn more about these relationships requires reliable earnings data with which to calculate AIME, as well as health and wealth data. This information is available from the Health and Retirement Study (HRS) and its restricted earnings data counterpart from the Social Security Administration (SSA). The HRS is a nationally representative, biennial panel survey of older Americans and their spouses. The survey began in 1992 with a cohort of people born between 1931 and 1941. They were interviewed every two years from 1992 through 2006. In 1998, the HRS was expanded to include several other birth cohorts, creating a sample of Americans over age 50. In 2004, an additional cohort of people born between 1948 and 1953 was also added. We merge the HRS data with the Respondent Cross-Year Summary Earnings file, which contains restricted SSA Administrative data on quarters worked, covered earnings, and benefits received since $1951 .^{6}$

From the restricted data, we calculate AIME using the Primary Insurance Amount (PIA) formula. AIME is then indexed to the national wage, so that it is comparable across birth cohorts. In the discussion below, note that any references to AIME refer to this ratio of AIME to the national average monthly wage at age 62. We use the SSA-linked data to

\footnotetext{
${ }^{6}$ When using the restricted data, it is necessary to drop individuals who did not give permission to have their survey data linked to SSA administrative data. This is assumed to result in little to no bias.
} 
find out if it is possible to target individuals who may be disproportionately adversely affected by a higher EEA due to their having lower life expectancies.

\section{A. The sample}

The analysis in this paper uses a sub-sample of individuals whose earnings records are complete, or close to complete, for their lifetimes. The available restricted earnings data covers the period 1951 to $2006 .^{7}$ In order to get a reasonable estimate of the highest 35 years of earnings (and thus AIME), we ideally should use the 1930 birth cohort (who were 21 in 1951) through the 1944 cohort (age 62 in 2006). However, a rough approximation of the age-earnings profile suggests that for most people, their highest 35 years of earnings occur from age 25 to 60, assuming no earnings gaps. Because people born in 1926 are 25 in 1951, AIME measured from 1951 onwards should be reasonably accurate, even though the first few years of adulthood are not observed. Similarly, people born in 1946 are 60 in 2006. Therefore, we take a slightly looser approach and restrict the birth cohorts to 1926 to 1946.

To ensure that AIME is calculated accurately, further restrictions are needed due to the nature of the data. Respondents are given the opportunity over various waves of the survey to begin and renew their permission to link SSA records with their HRS responses. For the HRS cohort, the first permissions were granted in 1992 and have been updated in 1994, 1998, 2004, and 2006. The restricted earnings data for an individual only covers the years prior to and including the permission year; so for individuals with a permission year of 1992 only, their earnings history stops in 1992. For those born in 1932 and earlier, this is of no consequence, since they are already 60 years old in 1992; however, for those born after

\footnotetext{
${ }^{7}$ The length of this period depends on the permissions for the restricted data; some of the earnings streams stop as early as 1992. See http://hrsonline.isr.umich.edu/index.php?p=resprodinfo\&iyear=1051 for more information on the permissions years.
} 
1932 (of which there are many in the HRS cohort), their earnings data are incomplete. We therefore drop individuals who are not observed to have died in the wave following their permission year, to avoid including people with artificially low AIME. ${ }^{8}$

The sub-sample used here is further reduced. First, it excludes individuals who are not alive at age 62. Because Social Security benefits become available at that age, our analysis is conducted conditional on reaching age 62. Second, it excludes immigrants (individuals born outside the U.S.), since they may have low numbers of quarters worked due to having worked outside the U.S. before immigrating, causing the AIME to not accurately reflect their lifetime earnings. ${ }^{9}$ Third, the sub-sample excludes single individuals with less than 40 quarters of covered earnings and couples without a spouse with at least 40 covered quarters, who are all ineligible for Social Security benefits. Fourth, the sub-sample excludes people who have a substantial number of quarters of work that is not covered by Social Security. In particular, we exclude individuals whose longest self-reported tenure on a job is more than 10 years greater than the corresponding number of years worked (total quarters divided by four) according to their SSA record. Fifth, individuals whose selfreported longest job was with a government employer are dropped because many government jobs are not covered by Social Security. Finally, the sub-sample excludes individuals who report ever having been on DI or SSI. ${ }^{10}$ This group is excluded because our

\footnotetext{
${ }^{8}$ The 666 individuals who are dropped due to insufficient earnings data, as a result of a permissions year being too early in their working lives, are not more likely to be female, nor do they have different wealth, on average, than the people who remain in the sample. However, they do have lower years of education and lower rates of marriage at age 62. Our analysis could be biased towards finding no effect of being in a low AIME category, due to the fact that we drop a lot of individuals with low AIME. Our results and conclusion are not sensitive to dropping these individuals (see Appendix B).

${ }^{9}$ The same could be said of any other group with sizeable non-covered earnings, such as the self-employed and state and local government employees. However, in the interest of sample size, we make no other restrictions.

${ }^{10}$ To determine whether an individual has ever been on DI/SSI, we use the RAND variable 'radiget' (RAND HRS data version i). We do not use the information in the restricted SSA data regarding the type of benefits
} 
policy proposal assumes that the DI program - and in particular the application requirements - would not change. Therefore, those who are on DI would presumably still apply for and qualify for DI even if the FRA were to change. This approach does not mean that changes to the EEA and FRA would have no impact on DI applications, since the value of DI benefits appears relatively more valuable as the FRA rises (see Duggan et al. 2007). However, this secondary effect is not considered in this analysis.

The resulting sample used in the estimation in Section B below contains 1,955 individuals, over 90 percent of whom are from the original HRS cohort. ${ }^{11}$ Most of the individuals in this sample were born between 1931 and 1936, though the birth years range from 1929 to 1946.

\section{B. AIME and Mortality}

We hypothesize that AIME and mortality are negatively related, that is, as AIME rises, mortality falls (and life expectancy rises). This relationship is mostly due to the positive effects of wealth, health, and their interaction.

\section{Mortality at Age 70}

The investigation of the relationship between AIME and mortality is complicated by two features. First, women generally have low AIME, because of low quarters worked, low earnings, or both. However, they tend to have higher than average life expectancy because of their gender. Second, many workers in a given year do not have covered earnings. Examples of workers without covered earnings are state and local government employees in

received because this would lower our sample size considerably. However, it is important to point out that the self-reports and the benefits file show similar rates of disability coverage.

${ }^{11}$ This amounts to 1,696 households as of wave 1 of the survey. However, the number of households is a bit misleading, as it requires that both spouses have restricted SSA data. 
jobs with public pension plans, of which there are roughly five million, as well as federal government employees hired before 1984 (GAO 2003). ${ }^{12}$ While the first problem is difficult to deal with, we solve the second one by the exclusions discussed above.

We begin by examining observed mortality for our sample at age 70 and younger ${ }^{13}$ as it varies across AIME quintiles. ${ }^{14}$ We assigned all individuals to different AIME quintiles combining women and men together based on their own or maximum AIME between two spouses. Since women tend to earn less due to a lower level of earnings and fewer years in the labor force, the first quintile based on own AIME predominantly consists of women, while the fifth quintile is dominated by men. When we look at the mortality rate by age 70 across gender we preserved the ranking, that is number of men/women in the first and fifth quintile is not the same when we look at men and women separately. ${ }^{15}$ Table 3 shows a strong positive relationship between own AIME and life expectancy for men, as has been found in other studies of the correlation between measures of economic status and life expectancy. The relationship is weaker for women, but women with the highest levels of AIME have a higher probability of survival to age 70 than do other women. The pattern disappears, however, when men and women are pooled. The main explanation is that the higher own AIME categories are dominated by men, and the lower categories are dominated by women. This means that when men and women are ranked by own AIME and pooled

\footnotetext{
${ }^{12}$ In addition, some self-employed individuals may underreport earnings to the SSA. However, the nonfarm and nonprofessional (farm and professional) self-employed began paying payroll tax in 1951 (1954), though they contributed at a lower total rate (including the employer contribution) until 1985 (for a history of contribution rates, see http://www.ssa.gov/OACT/ProgData/taxRates.html). We leave the self-employed in the sample.

${ }_{13}^{13}$ Age 70 is chosen rather arbitrarily.

${ }^{14}$ This exercise requires a sample in which the person is observed at age 62, and is also observed as either dead or alive at age 70 or older.

${ }^{15}$ We preserve the ranking because we would like to demonstrate that the rule which is based on the ranking across both sexes will work for men and women and that the relationship between mortality and AIME is actually stronger that it is seen in the second and third columns due to pooling women and men together.
} 
together (Column 1), mortality is low for the bottom AIME group for two reasons: 1)

women and men have different life expectancies and 2) some of the women with low own AIME may have a high earner husband and thus have high life expectancy due to the higher socioeconomic status of the household. Moreover, mortality and own AIME seem to be only weakly related. ${ }^{16}$

To address this issue, this paper calculates a new measure - max AIME. Max AIME is the AIME for single, never-married persons and the maximum of the husband's and wife's AIME for married persons and formerly married persons who were married sufficiently long (ten years) so that one spouse could receive benefits based on the other spouse's earnings record. Because the max AIME measure takes into account the earnings of the other spouse, it is a household measure.

Table 3 suggests that while own AIME does a poor job of targeting, max AIME does a fairly good job for women but less well for men in targeting people with low life expectancy. That table shows that 11.5 percent of women in the bottom max AIME quintile and 14.3 percent of men who were alive at age 62 have died by age 70 . For women, this percentage is substantially higher than the percentage in other quintiles. For men, the percentage is higher for the other quintiles, except the second quintile, but the difference is not nearly as great as for women.

Thus, because it does a better job of targeting than AIME, we use the max AIME to rank people. ${ }^{17}$ For the most part, max AIME is own AIME for single and married males and

\footnotetext{
${ }^{16}$ Discussing mortality of low (own) AIME men can in general be complicated by the fact that this group may include the self-employed and government employees, who can have low covered quarters and low AIME but long self-reported years of work and low mortality. However, we drop them from the sample, as discussed in the text.

${ }^{17}$ Divorced individuals are considered single. In order to have a spouse's AIME information, the restricted data for both spouses must be available. For about 10 percent of married individuals, their spousal information is not available, and they are assigned a max AIME equal to their own AIME.
} 
single females, and husband's AIME for married females. ${ }^{18}$ This is true about 90 percent of the time (see Table A1). The max AIME ranking appears to obviate the complication of married, non-working but well-off women. This result may occur because of the marriage of men and women with similar characteristics, including similar life expectancies assortative mating. For these reasons, in the rest of the paper, all analyses that depend on an AIME ranking use max AIME. In columns 2, 4, and 6 of Table 3, a clearer negative correlation emerges between mortality at age 70 and AIME quintile. The highest and lowest AIME quintiles seem to have the most distinct mortality shifts, while the middle groups are more similar to each other. However, we expect to see a stronger relationship between mortality and AIME as our sample of individuals gets older. The sample under consideration did not reach average life expectancy for their birth cohort due to the short panel of data.

\section{Hazard Models}

The problem with looking only at mortality by age 70 is that people who drop out of the sample or who do not reach 70 by the 2006 wave are not included in the analysis above. Ignoring this type of data censoring limits the sample size and can potentially bias the results. A hazard model (or survival analysis), in contrast, allows for both left and right censoring of the data, and nearly doubles the sample size: the sample size goes from 1,955 to 3,934 individuals. ${ }^{19}$

Very generally, a hazard model relates survival to a set of chosen covariates based on whether individuals are observed to die, and if so, their ages of death. In an ideal world,

\footnotetext{
${ }^{18}$ The "unmarried" individuals' max AIME figure may not be their own if their spouse has been observed at some point in the eight waves of the survey.

${ }^{19}$ For completeness, hazard model results using the sub-sample in Section 3B.1 (Mortality at 70) are presented in Table A4.
} 
a hazard model for survival conditional on being alive at age 62 would be estimated with data containing the age of death for every individual. However, the HRS sample used here has two weaknesses: 1) the oldest people in the sample are only 77 , so the data does not contain many deaths on which to base identification, and many people are not observed to die (about 20 percent of the individuals in our sub-sample die); and 2) the amount of time over which individuals are observed falls with year of birth. The model can be adjusted to take into account these censoring issues, though the precision of the estimation is compromised.

The first step of the hazard function analysis is to use a Kaplan-Meier estimator, which estimates the survival function non-parametrically by maximum likelihood. The Kaplan-Meier results can be seen graphically in Figure 3. The graph shows survival rates as a function of time; in this case, age is synonymous with time. The lowest household income quintile group, maxAIME_1, has persistently lower survival rates, while the highest income quintile group, maxAIME_5, has elevated survival rates.

Next, we turn to a parametric hazard model, in which the functional form of the underlying hazard function is fully specified the following way:

$$
h(i, t)=\exp \left(x_{i, t} B\right) \exp (\gamma t)
$$

When $\gamma$ is positive, the hazard function increases exponentially with age. The hazard function also shifts proportionately, depending on the characteristics $x_{i, t}$ of individual $i$ at time $t$. Similar to the existing literature on mortality modeling, we use a Gompertz functional form for the baseline hazard (see e.g., Finkelstein et al. 2009). The model is estimated for individuals aged 62 and older. A criticism of the Gompertz model is that it does not estimate mortality well at older ages; however, the maximum age in our sample is 77, so this distributional assumption should be well suited to the data at hand. 
Results of the parametric hazard model are presented in Table $4 .^{20}$ The explanatory variables of the model are confined to max AIME and quarters of work, the two key variables known to the SSA. ${ }^{21}$ The coefficients reported in Table 4 are hazard ratios. A hazard ratio greater than (less than) 1 indicates that the group has a higher (lower) probability of death than the reference group. The reference category is the middle max AIME quintile, or maxAIME_3.

In the first set of results in Column 1, we do not control for quarters of covered earnings. These results are consistent with the summary statistics. The strongest finding is that the bottom AIME quintile has a significantly higher rate of death than any other group. That result is only significant at the 10 percent level, perhaps because of the limited number of deaths that have occurred in the sample, due to the relatively low maximum age in the sample. As people in the sample get older, we expect to have stronger relationship between AIME and mortality. The other quintiles are relatively similar. The highest group has the best survival rates, but the coefficient on maxAIME_5 is statistically insignificant. Using the maximum of quarters worked (constructed analogously to the max AIME) also seems like a promising categorization mechanism, as this variable is highly predictive of life expectancy. However, people with low numbers of covered quarters have higher mortality suggesting that the policy rule would involve forcing people with already longer working lives to stay even more years in the labor force which may be an unacceptable basis for changing the Social Security benefit rules (Haverstick et al 2008).

\footnotetext{
${ }^{20}$ Estimates of the gamma may differ from the estimates for the population in general found in previous literature due to sample being unrepresentative of the US population due to the scope of the research question. In addition, we observe individuals over a very short period of time, in their 60s and early 70 s, when mortality rates are low.

${ }^{21}$ We also experimented with using a continuous AIME variable, along with squared and cubed terms, as opposed to quintile dummies. The quintiles proved easier to interpret in the context of the flexible FRA policy frame.
} 
For completeness, results are also presented with a control for the quintile of own covered quarters. $^{22}$ The goal of adding covered quarters is to control for wealthy, nonworking homemakers, those with non-covered quarters, and high-earning individuals with long working lives. Both of these groups are expected to have low mortality. The hazard ratios provide evidence that this assumption is true, since the hazard ratios for Own_quarters_1 and Own_quarters_5 are both less than 1 and statistically significant. The hazard ratios for the AIME quintiles, however, are similar to the regression without the control for quarters.

Altogether, the results indicate high mortality/low life expectancy for people at the bottom of the max AIME distribution. The results also provide weak evidence that people at the top of the max AIME distribution have relatively low mortality. These results are consistent with an extensive literature linking mortality to income. The precision of these results could be enhanced by using more covariates, such as gender and race. However, for the goal of designing an FRA policy, the relevant tools are max AIME and covered quarters, as these are the instruments available to SSA. Furthermore, despite known differences in life expectancy across certain characteristics such as gender and race, the distributions overlap substantially and no policy based on such characteristics would be ethically acceptable. $^{23}$

Therefore, the hazard model suggests that for the bottom max AIME quintile, a flexible FRA might be justified based on differences in life expectancy. A more standard

\footnotetext{
${ }^{22} \mathrm{We}$ also experimented with including the maximum of own or spouse's quarters, but these results were extremely difficult to interpret due to the high correlation between AIME and covered quarters.

${ }^{23}$ Simple probit regressions of mortality at 70 as a function of AIME quintiles show that the low AIME groups still have higher mortality after controlling for basic demographic characteristics.
} 
FRA that has a simple automatic adjustment for rising life expectancy may be relevant for all others.

\section{AIME and Vulnerability}

While we are interested in understanding how AIME and mortality are linked, we also investigate the separate but related issue of whether targeting those with low max AIME would achieve the goal of protecting the elderly from poverty. More specifically, this section aims to establish a connection between max AIME and economic vulnerability, where vulnerability encompasses many dimensions such as low education, low wealth, poor health, and health limitations to working. In other words, are we targeting the "right" households when we choose those with low max AIME? We remind the reader that we have already shown that max AIME provides better targeting than AIME when the targeting criterion is low life expectancy.

Table 5 presents summary statistics for individuals across max AIME quintiles. For women, it is generally true that the lowest max AIME quintile contains women who are relatively worse off, both in terms of health and wealth. However, it is important to remember that men represent about a third (34 percent) of the lowest max AIME quintile and that a flexible FRA would need to take into account non-covered work, as is done in calculating Social Security benefits. In addition to being a better predictor of life expectancy, max AIME is as effective as own AIME in identifying vulnerable individuals (see Appendix Table A2). In some case, max AIME is better at identifying vulnerable women, for example, those who are unmarried or in poor health. Thus, lowest max AIME quintile contains only 41 percent of married women and 24 percent of women in poor health 
while lowest own AIME quintile contains 85 percent of married women and only 16 percent of women in poor health.

Table 6 shows similar statistics but at the household level. This table highlights the fact that targeting the lowest max AIME quintile may be a way to find those with health problems who find working difficult. Indeed, one of the more important aspects of vulnerability for Social Security policy is health limitations to working. Individuals who are too unhealthy to keep working, but who do not qualify for Disability Insurance, would be most affected by any rise in the EEA. These people may be of particular concern to policymakers looking to change the rules relating to the EEA and the FRA. Therefore, we include results on the relationship between max AIME and health limitations to working at one's EEA. Because the literature on the earnings and disability/health problems is well established, we present only brief evidence using a multivariate framework.

The findings of this exercise mirror existing research: max AIME and health limitations to working are indeed strongly related. Table 7 shows results of a simple probit regression; the dependent variable is health limitations to working at age 62 (binary). ${ }^{24}$ While the model is static, the exogeneity of max AIME is a strong assumption, and the direction of causality is difficult to argue definitively, the results still provide some support for the contention that low max AIME and inability to work go hand-in-hand. Further development of this model is left for future work.

\section{Hazard Model Robustness Checks}

\footnotetext{
${ }^{24}$ In the 2004 wave of the HRS survey, individuals who had reported having a health limitation to working in the previous wave skipped this question. We therefore impute the value of this variable for these individuals.
} 
Although we have already demonstrated that max AIME is better correlated to mortality than AIME, we do a further check as to how well max AIME predicts mortality and compare predictive power of our model with max AIME relative to the predictive power of the model with basic demographic data. To do so, we first predict the hazard rate based on the covariates (max AIME category and own quarters worked). Then, using a randomly generated, uniformly distributed variable (bounded between 0 and 1), each observation is assigned a status of predicted alive or predicted dead. This exercise shows that for the most part, at ages under 74, the frequency of actual death in the HRS is higher than the frequency of predicted death. Therefore, the model generally under-predicts mortality, and thus overpredicts the probability of living from one period to the next.

To get an idea of the predictive power of max AIME and quarters worked as compared to demographic characteristics, we run a similar hazard model on the same sample using the following covariates: a gender dummy, a non-white dummy, an Hispanic dummy, a dummy for college education, a dummy for being married at age 62, a dummy for having fair/poor health at age 62, and total assets at age 62 (in 2006 inflation-adjusted dollars). The results of this specification are shown in Table A3. Neither model is an exact match to the true mortality curve, but the degree of inaccuracy is similar across the two models, and both tend to underestimate mortality.

To summarize, the mortality model based on max AIME provides conservative estimates of the relationship between max AIME and life expectancy, as the hazard model generally underpredicts the mortality rate (Type II error). This is most likely due to the small sample sizes (for example, 23 deaths out of 2,448 people observed at age 67 , who were alive at age 66), and to the fact that our AIME sample prevents us from using the top 
of the age distribution. Indeed, comparing Table 8 and Figure 4 (discussed in more detail below), it is clear that the observed deaths in our restricted sample are only those for people who have died relatively young. This makes an evaluation of the predictive ability of our model very difficult. However, another explanation for the lower estimates of mortality rate than we observe in the data could be accidental death that is not related to max AIME, thus overstating the size of the Type II error.

\section{A Flexible FRA}

As shown above, a flexible FRA might be desirable for two reasons. First, it could protect people in households with low lifetime earnings and thus a low max AIME.

Although this is an imperfect mechanism by which to identify such households, Section $2 \mathrm{C}$ indicates that low max AIME is also correlated with health problems and difficulty working. Second, if life expectancy is correlated with max AIME, it could also be targeted to protect people with low life expectancy. A flexible FRA therefore could be based on the max AIME of workers. Workers in households with lower lifetime earnings, and thus a lower max AIME, would have their benefits calculated based on a lower FRA than would workers with higher max AIMEs.

To determine a feasible structure for the flexible FRA policy that is based on max AIME quintile, it is important to establish the differences in predicted mortality across max AIME groups. This is first examined using the limited number of observed deaths in the sample. In Table 8, the average years of life remaining from age 62, among those who are observed to die before 2006, show that indeed even in the small sample it appears that life 
expectancy is low for the bottom group. ${ }^{25}$ Using the results of our hazard model, median years of life remaining at age 62 are predicted. The distribution of median survival years by max AIME quintiles are summarized in Figure 4; they differ within max AIME quintiles due to the control for quarters worked.

Figure 4 shows that predicted life expectancy for the bottom quintile tends to be several years below that of the other quintiles. In addition, the evidence in Section III also suggests that the bottom max AIME quintile tends to have worse life outcomes, in terms of wealth and health, than others. Therefore, the policy prescription laid out in this paper focuses on building a flexible FRA around the cutoff between the lowest 20 percent of the max AIME distribution, and everyone else. ${ }^{26}$

Figure 5 illustrates a simple example of implementing a policy rule when the FRA is based on the ratio of max AIME to the National Average Monthly Earnings (NAME), as in our analysis above. Low-income workers making less than 50 percent of the national wage would be eligible to claim full retirement benefits at age 67, as in current law. The FRA would gradually increase by month as max AIME approaches National Average Monthly Earnings to avoid distortion at the cutoff point. Under this example, lower-income workers would not be adversely affected by the increase in FRA, and thus would not experience a decline in the replacement rate. The replacement rate and the level of benefits would decline for workers with average and high AIMEs, but presumably policymakers are less concerned about the replacement rate and level of benefits for these workers because they are more

\footnotetext{
${ }^{25}$ This difference in life expectancy is also confirmed using the self-reported probability to living to age $75+$. The bottom max AIME quintile has an average expected probability of living to age 75 that is about 5 percentage points lower than the middle AIME groups.

${ }^{26}$ A feasible alternative would be to use the bottom 25 percent. In addition, life expectancy will continue to improve, so tying the FRA to increases in life expectancy could be an important element of the policy rule, while keeping in mind the dispersion in the gains in life expectancy across income groups. Also, the minimum replacement rate for low-income workers is an important issue since they rely heavily on Social Security, but this issue is left for further research.
} 
likely to also be covered by an employer-provided pension than are workers with low AIME (Table 2). ${ }^{27}$ This change would improve the progressivity of Social Security, but it is beyond the scope of this paper to fully assess that effect.

The question is how well a flexible FRA policy targets the vulnerable population? The proposed flexible FRA protects households with low lifetime income by definition as max AIME represents average lifetime income for the households. ${ }^{28}$ Table A5 shows that average max AIME for the household in the lowest quintile is about $\$ 13,000$ while these households have only about $\$ 97,000$ total household wealth including housing at age 62 (Table 6). Raising the FRA would push these households below poverty. Unfortunately, it is too early to say how well our proposed policy rule targets households with low life expectancy as the oldest respondent born in 1926 reached age 80 in 2006 - the last year we observe our sample. ${ }^{29}$ However, Table 3 demonstrates that the flexible FRA has a good potential at doing so as about 14.3 percent of men and 11.5 percent of women who form the households in the lowest quintile died by age 70 compared to 2.9 percent of men and 2.0 percent of women in the top quintile.

This paper leaves the proposed flexible FRA simple; the policy is meant to be a suggestion of a possible framework for thinking about this issue. A more complete analysis of the policy would require much more data on population mortality, as well as the actuarial expertise of the SSA. However, the exact structure of the flexible FRA could be calibrated so that the net effect on Social Security's finances would be equivalent to an across-the-

\footnotetext{
${ }^{27}$ An issue that may be of concern is declining political support for Social Security if the replacement rate for high-income workers is eroded too far.

${ }^{28}$ There are two types of people who may have low AIME: 1) low earners and workers with volatile employment and 2) workers who held government jobs during their working years. However, we exclude people having government jobs from the sample.

${ }^{29}$ According to the Social Security Administration (2006), the average male and average female alive at age 62 should expect to live to age 81 and 84 respectively. Thus, none of the households reached average life expectancy.
} 
board increase in the FRA. It would also need to be structured so that people at the margin between different FRAs based on their max AIME would not face a reduction in benefits with a higher AIME.

\section{Implications of a Flexible FRA}

The flexible FRA would for some people reduce the additional benefits received based on working longer and retiring later because their additional work would result in them being subject to the higher FRA. It thus would reduce the incentive to work for those people. For this reason, it may be desirable to base the FRA on the worker's max AIME calculated at age 62 or a younger age, so that work at older ages would not result in the worker facing a higher FRA, and so that the incentive to work at older ages would not be reduced.

In addition, it is worth noting that a flexible FRA as proposed would have a relatively small impact on the labor force participation incentives for those with low AIME, as their FRA would be the lowest, and perhaps rise at a lower rate as life expectancy grows in the future. Those in the middle of the AIME distribution, for whom Social Security benefits comprise a significant portion of their retirement income, but who would not face a lower FRA under the flexible FRA policy rule, would have the largest incentive to keep working. They are already the group that is most likely to work beyond their FRA (see Table A6), so it is unclear how much more they will in fact work with a change in the FRA. An analysis of the effects on labor force participation is beyond the scope of this paper; we refer the reader to Mastrobuoni (2009), who provides a new look at the relationship between labor supply and the FRA. 
Some people may see it as unfair for lower-income persons to have a lower retirement age than those with higher incomes persons. This objection would be based on a misunderstanding. The FRA, despite its name, has nothing to do with the age at which a person is eligible to retire, which is age 62. All workers working past the FRA, up to age 70 , see further increases in their benefits because actuarial adjustments for postponed retirement are made up to age 70 .

The political economy of Social Security reform may make it desirable that a reform that contains negatives - benefit cuts and tax increases - also contain positives. A flexible FRA would be a positive for low-income workers, but would make larger benefit cuts than otherwise for high-income workers. It would increase the progressivity of Social Security, which studies have found is at most mildly progressive.

Other household measures related to the AIME could also possibly be used for constructing a flexible FRA. For example, instead of using the max AIME, the AIME on which the person's retirement benefits were based could be used. For some couples, if their AIMEs were similar, the retirement benefits of the spouse with the lower AIME would be based on their AIME, rather than on the max AIME, which would be their spouse's AIME. Another alternative would be to construct a family AIME, which would be based on the combination of the husband's and wife's AIME, divided by a scaling factor. We save the exploration of those alternatives for future work.

\section{Conclusion}

We have investigated the policy option of a flexible full retirement age (FRA) as a way of dealing with inequities in Social Security policies arising from the large differences 
in life expectancy across groups. With a flexible FRA, future increases in the FRA to restore solvency to Social Security would be linked to a household measure of the AIME, with lower increases for people with lower AIME. Specifically, in this paper we have investigated the possibility of using the max AIME, which is the AIME for a single person and the maximum of the AIME for a husband or wife. We have shown that while the AIME is not well targeted by life expectancy, the max AIME could be used to construct a policy that would be targeted by life expectancy, as well as by low lifetime income. 


\section{References}

Brown, Jeffrey. 2000. "Differential Mortality and the Value of Individual Account Retirement Annuities." NBER Working Paper No. 7560. Cambridge, MA.

Brown, Jeffrey. 2003. "Redistribution and Insurance: Mandatory Annuitization with Mortality Heterogeneity." Journal of Risk and Insurance 70(1): 17-41.

Brown, Jeffrey, Julia Coronado and Don Fullerton. 2009. "Is Social Security Part of the Social Safety Net?” CESifo Working Paper No. 2610.

Cohen, Lee, C. Eugene Steuerle, and Adam Carasso. 2001. "Social Security Redistribution by Education, Race, and Income: How Much and Why?" Unpublished working paper.

Coronado, Julia, Don Fullerton and Thomas Glass. 2000. "The Progressivity of Social Security.” NBER Working Paper No. 7520. Cambridge, MA.

Duggan, Mark, Perry Singleton, and Jae Song. 2007. "Aching to retire? The rise in the full retirement age and its impact on the social security disability rolls." Journal of Public Economics 91(7-8): 1327-1350.

Finkelstein, Amy, James Poterba, and Casey Rothschild. 2009. "Redistribution by Insurance Market Regulation: Analyzing a Ban on Gender-based Retirement Annuities." Journal of Financial Economics 91(1): 38-58.

Freedman, Vicki, Eileen Crimmins, Robert Schoeni, Brenda Spillman, Hakan Aykan, Ellen Kramarow, Kenneth Land, James Lubitz, Kenneth Manton, Linda Martin, Diane Shinberg, and Timothy Waidmann. 2004. "Resolving Inconsistencies in Trends in Old-Age Disability: Report from a Technical Working Group." Demography 41(3): 417-441.

Furman, Jason. 2007. "Coping with Demographic Uncertainty," NYU Wagner working paper, available at:

http://wagner.nyu.edu/performance/socialsecurity/demographicuncertainty.pdf.

Government Accountability Office. 2003. "Social Security: Issues Relating to Noncoverage of Public Employees." Report number GAO-03-710T.

Goesling, Brian. 2007. "The Rising Significance of Education for Health?" Social Forces 85(4): 1621-1644.

Gustman, Alan and Thomas Steinmeier. 2001. "How Effective is Redistribution under the Social Security Benefit Formula?" Journal of Public Economics 82(1): 1-28.

Haverstick, Kelly; Sapozhnikov, Margarita; Triest, Robert K and Zhivan, Natalia. 2008. 
"An Elastic Earliest Eligibility Age for Social Security." Center for Retirement Research at Boston College, Issue In Brier no. 8-2, February.

Harris, Amy and John Sabelhaus. 2005. "How Does Differential Mortality Affect Social Security Finances and Progressivity?" CBO Working Paper 2005-5.

Liebman, Jeffrey, Maya MacGuineas, and Andrew Samwick. 2005. "Nonpartisan Social Security Reform Plan.” Available at http://www.hks.harvard.edu/jeffreyliebman/ lms_nonpartisan_plan_description.pdf.

Liebman, Jeffrey. 2002. "Redistribution in the Current US Social Security System." In M. Feldstein and J. Liebman, eds., Distributional Aspects of Social Security and Social Security Reform. Chicago: University of Chicago Press, 11-48.

Mastrobuoni, Giovanni. 2009. "Labor supply effects of the recent social security benefit cuts: Empirical estimates using cohort discontinuities." Journal of Public Economics 93(11-12): 1224-1233.

Meara, Ellen, Seth Richards and David Cutler. 2008. "The Gap Gets Bigger: Changes In Mortality and Life Expectancy, By Education, 1981-2000."Health Affairs 27(2): 350-360.

Mermin, Gordon and C. Eugene Steuerle. 2006. "Would Raising the Social Security Retirement Age Harm Low-Income Groups?" Urban Institute: The Retirement Project Brief Series No. 19.

Munnell, Alicia, Mauricio Soto and Alex Golub-Sass. 2008. "Will People Be Healthy Enough To Work Longer?" Working Paper 2008-11. Chestnut Hill, MA: Center for Retirement Research at Boston College.

Murray, Christopher J. L., Sandeep C. Kulkarni, Catherine Michaud, Niels Tomijima, Maria T. Bulzacchelli, Terrel J.Iandiorio, and Majid Ezzati.2006. "Eight Americas: Investigating Mortality Disparities across Races, Counties, and Race- Counties in the United States." PLoS Medicine vol. 3, Issue 9, September. Available at http://medicine.plosjournals.org/perlserv?request=getdocument\&doi=10.1371/journal.pmed.0030260.

Oeppen, Jim and James Vaupel. 2002. "Broken Limits to Life Expectancy," Science 26: 1029-1031.

Olshansky, S. Jay, Douglas Passaro, Ronald Hershow, Jennifer Layden, Bruce Carnes, Jacob Brody, Leonard Hayflick, Robert Butler, David Allison, and David Ludwig. 2005. "A Potential Decline in Life Expectancy in the United States in the 21st Century," New England Journal of Medicine 352(11): 1138-1145. 
Schoeni, Robert F., Linda G. Martin, Patricia M. Andreski, and Vicki A. Freedman. 2005. "Persistent and Growing Socioeconomic Disparities in Disability Among the Elderly: 1982-2002." American Journal of Public Health 95(11): 2065-2070.

Social Security Advisory Board. 2005. "Social Security: Why Action Should Be Taken Soon." Washington, DC.

Shoven, John and Gopi Shah Goda. 2008. "Adjusting Government Policies for Age Inflation.” NBER Working Paper 14231. Cambridge, MA.

Turner, John. 2008. "Social Security Financing: Automatic Adjustments to Restore Solvency.” Pension Policy Center report prepared for AARP, October.

U.S. Department of Health and Human Services. National Center for Health Statistics.2006. "Trends in Health and Aging." Hyattsville, MD. Available at http://www.cdc.gov/nchs/agingact.htm.

U.S. Social Security Administration. 2008. The 2008 Annual Report of the Board of Trustees of the Federal Old-Age and Survivors Insurance and Federal Disability Insurance Trust Funds. Washington, DC: U.S. Government Printing Office.

U.S. Social Security Administration. 2008. "National Average Wage Index.” Available at: http://www.ssa.gov/OACT/COLA/AWI.html.

Waldron, Hilary. 2007. “Trends in Mortality Differentials and Life Expectancy for Male Social Security-Covered Workers, by Socioeconomic Status.” Social Security Bulletin 67(3): 1-28.

Zhang, Qi and Youfa Wang. 2004. "Trends in the Association between Obesity and Socioeconomic Status in U.S. Adults: 1971 to 2000," Obesity Research 12(10): 1622-1632.

Zhivan, Natalia; Sass, Stephen A.; Sapozhnikov, Margarita; and Haverstick, Kelly. 2008. "An Elastic Earliest Eligibility Age for Social Security." Center for Retirement Research at Boston College, Issue In Brief no. 8-2, February. 
Table 1. Life Expectancy at Age 65

\begin{tabular}{l|c|c|c|c} 
Year & $\begin{array}{c}\text { White } \\
\text { Men } \\
\text { (years) }\end{array}$ & $\begin{array}{c}\text { White } \\
\text { Women } \\
\text { (years) }\end{array}$ & $\begin{array}{c}\text { Black } \\
\text { Men } \\
\text { (years) }\end{array}$ & $\begin{array}{c}\text { Black } \\
\text { Women } \\
\text { (years) }\end{array}$ \\
\hline 1950 & 12.8 & 15.1 & 12.9 & 14.9 \\
\hline 1960 & 12.9 & 15.9 & 12.7 & 15.1 \\
\hline 1975 & 13.7 & 18,1 & 13.7 & 17.5 \\
\hline 2003 & 16.9 & 19.8 & 14.9 & 18.5 \\
\hline $\begin{array}{l}\text { Change in life } \\
\text { expectancy from 1950 } \\
\text { (from 1960) }\end{array}$ & 4.1 & 4.7 & 2.0 & 3.6 \\
\hline
\end{tabular}

Sources: U.S. Department of Health and Human services (2006) and authors' calculations.

Table 2. Annual Social Security Benefit Claimed at the Age 62 if the FRA in 2008 Were 65 or 67

\begin{tabular}{l|c|c|c|c|c|c}
\hline \multirow{2}{*}{ Earner type } & \multicolumn{2}{|c|}{ FRA at 65 } & \multicolumn{2}{c|}{ FRA at 67 } & \multicolumn{2}{c}{ FRA at 69 } \\
\cline { 2 - 7 } & Benefit & $\%$ of poverty & Benefit & $\%$ of poverty & Benefit & $\%$ of poverty \\
\hline Low earner & $\$ 8,721$ & $\% 84$ & $\$ 7,631$ & $\% 73$ & $\$ 6,540$ & $\% 63$ \\
\hline Average earner & 14,541 & 140 & 12,723 & 122 & 10,905 & 105 \\
\hline High earner & 18,893 & 182 & 16,532 & 159 & 14,170 & 136 \\
\hline
\end{tabular}

Note: Following the Social Security Administration, a low earner makes 45 percent, an average 100 percent, and a high earner 160 percent of the national average wage, which was $\$ 41.335$ in 2008 . The poverty threshold for a one-person household in 2008 was $\$ 10,400$.

Sources: Author's calculations based on U.S. Social Security Administration (2008).

Table 3. Percent of Individuals in the Sample Observed Dead by Age 70, Conditional on Being Alive at 62

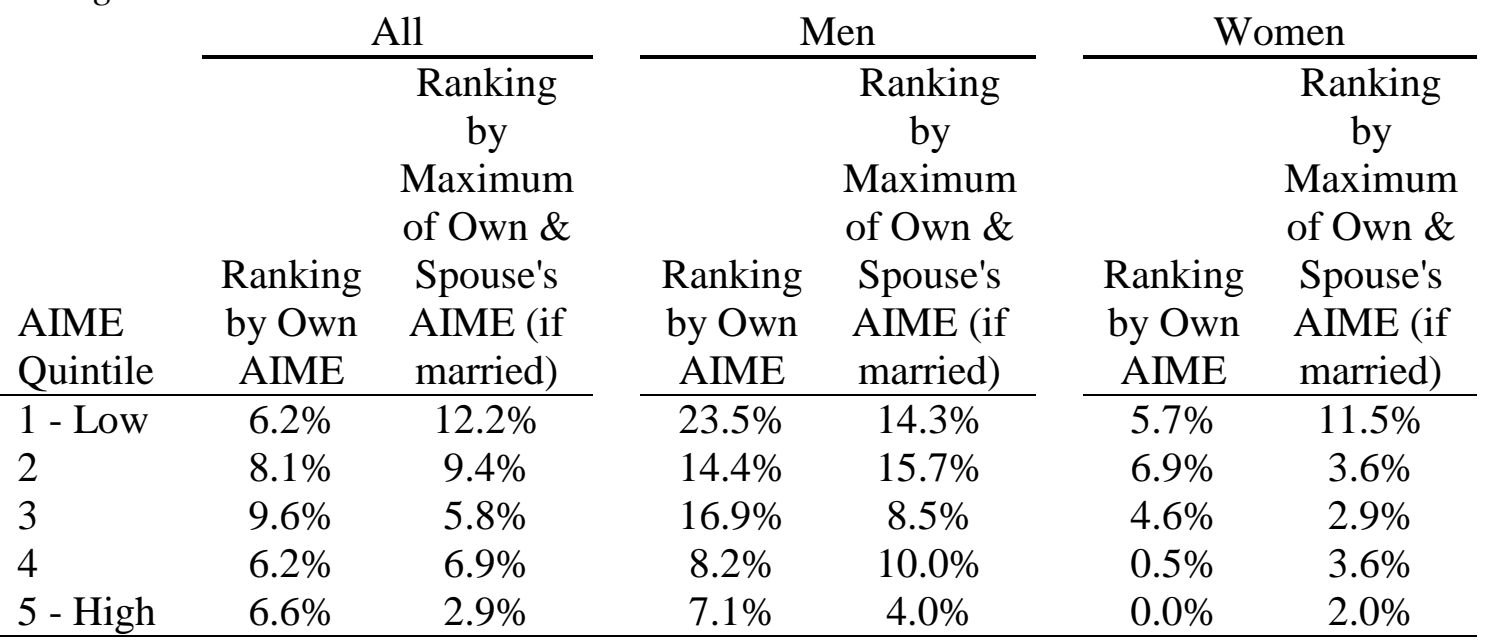

Source: 1992-2006 HRS.

Notes: Analysis weights for the wave when the individual is age 61/62 are used. When genders are separated, the sizes of the groups across max AIME quintiles differ. 
Table 4. Hazard Model Results, Conditional on Being Observed Alive at 62

\begin{tabular}{|c|c|c|c|c|c|c|}
\hline \multirow[b]{2}{*}{ Variable } & \multicolumn{2}{|c|}{1} & \multicolumn{2}{|c|}{2} & \multicolumn{2}{|c|}{3} \\
\hline & $\begin{array}{c}\text { Hazard } \\
\text { Ratio }\end{array}$ & Z-stat & $\begin{array}{c}\text { Hazard } \\
\text { Ratio }\end{array}$ & Z-stat & $\begin{array}{c}\text { Hazard } \\
\text { Ratio }\end{array}$ & Z-stat \\
\hline maxAIME_1 & 1.516 & $1.73^{*}$ & & & 1.386 & 1.33 \\
\hline maxAIME_2 & 1.123 & 0.44 & & & 1.046 & 0.17 \\
\hline maxAIME_4 & 1.142 & 0.53 & & & 1.169 & 0.62 \\
\hline maxAIME_5 & 0.599 & $-1.86^{*}$ & & & 0.650 & -1.58 \\
\hline Max_quarters_1 & & & 2.334 & $4.05 * * *$ & & \\
\hline Max_quarters_2 & & & 1.354 & 1.29 & & \\
\hline Max_quarters_4 & & & 0.325 & $-3.03 * * *$ & & \\
\hline Max_quarters_5 & & & 0.223 & $-3.7 * * *$ & & \\
\hline Own_quarters_1 & & & & & 0.518 & $-2.84 * * *$ \\
\hline Own_quarters_2 & & & & & 0.860 & -0.69 \\
\hline Own_quarters_4 & & & & & 0.762 & -1.17 \\
\hline Own_quarters_5 & & & & & 0.250 & $-4.31 * * *$ \\
\hline$\gamma$ & 0.170 & $8.34 * * *$ & 0.155 & $7.6 * * *$ & 0.166 & $8.17 * * *$ \\
\hline $\begin{array}{l}\text { Pseudo log } \\
\text { likelihood }\end{array}$ & $-2,9$ & 7,941 & $-2,8$ & 5,793 & $-2,9$ & 5,566 \\
\hline
\end{tabular}

Table 5. Summary Statistics for Individuals by Max AIME Quintile

\begin{tabular}{|c|c|c|c|c|c|}
\hline $\begin{array}{l}\text { Max AIME } \\
\text { quintile }\end{array}$ & $\begin{array}{l}\% \text { with } \\
\text { College } \\
\text { Degree }\end{array}$ & $\begin{array}{c}\% \\
\text { White }\end{array}$ & $\begin{array}{c}\% \text { with } \\
\text { Fair/Poor } \\
\text { Health at } \\
\text { age } 62\end{array}$ & $\begin{array}{c}\% \\
\text { Married } \\
\text { at age } \\
62\end{array}$ & $\begin{array}{c}\% \text { with } \\
\text { Health } \\
\text { Limitation } \\
\text { to Working } \\
\text { at age } 62\end{array}$ \\
\hline \multicolumn{6}{|l|}{ Women } \\
\hline$\overline{1-\text { Low }}$ & 15 & 83 & 24 & 41 & 26 \\
\hline 2 & 16 & 89 & 10 & 61 & 14 \\
\hline 3 & 12 & 92 & 6 & 82 & 13 \\
\hline 4 & 18 & 97 & 10 & 88 & 18 \\
\hline 5 - High & 23 & 97 & 11 & 95 & 15 \\
\hline \multicolumn{6}{|l|}{ Men } \\
\hline$\overline{1-\text { Low }}$ & 18 & 74 & 23 & 69 & 27 \\
\hline 2 & 15 & 92 & 21 & 75 & 21 \\
\hline 3 & 13 & 88 & 15 & 81 & 17 \\
\hline 4 & 24 & 95 & 11 & 92 & 12 \\
\hline 5 - High & 40 & 99 & 7 & 92 & 10 \\
\hline
\end{tabular}

Source: 1992-2006 HRS.

Notes: Analysis weights for the wave when the individual is age 61/62 are used. 
Table 6. Summary Statistics for Households by Max AIME Quintile

\begin{tabular}{|c|c|c|c|c|c|}
\hline $\begin{array}{l}\text { Max AIME } \\
\text { quintile }\end{array}$ & $\begin{array}{l}\% \text { HHs } \\
\text { without } \\
\text { College } \\
\text { Degree }\end{array}$ & $\begin{array}{c}\% \text { HHs } \\
\text { All White } \\
\end{array}$ & $\begin{array}{c}\% \text { HHs } \\
\text { with No } \\
\text { One in } \\
\text { Fair or } \\
\text { Poor } \\
\text { Health at } \\
\text { age } 62 \\
\end{array}$ & $\begin{array}{l}\% \text { HHs with } \\
\text { No One with } \\
\text { Health } \\
\text { Limitation to } \\
\text { Working at } \\
\text { age } 62 \\
\end{array}$ & $\begin{array}{c}\text { Median } \\
\text { Total HH } \\
\text { Wealth at } \\
\text { age } 62 \\
(2006 \$)\end{array}$ \\
\hline 1 - Low & 78 & 81 & 73 & 70 & 97,294 \\
\hline 2 & 77 & 89 & 80 & 76 & 145,717 \\
\hline 3 & 82 & 90 & 84 & 74 & 181,240 \\
\hline 4 & 72 & 96 & 81 & 72 & 297,473 \\
\hline 5 - High & 56 & 98 & 86 & 80 & 414,680 \\
\hline
\end{tabular}

Table 7. Probit Results for Having a Health Limitation to Working at Age 61/62, Marginal Effects

\begin{tabular}{|c|c|c|c|c|}
\hline \multirow[b]{2}{*}{ Variable } & \multicolumn{2}{|c|}{ Without AIME controls } & \multicolumn{2}{|c|}{ With AIME controls } \\
\hline & Coefficient & Z-stat & Coefficient & z-stat \\
\hline Female & 0.006 & 0.32 & -0.006 & -0.32 \\
\hline Non-white & -0.051 & $-1.91 *$ & -0.065 & $-2.48 * * *$ \\
\hline Hispanic & 0.045 & 0.75 & 0.021 & 0.37 \\
\hline Married at 62 & -0.041 & $-1.76^{*}$ & -0.008 & -0.34 \\
\hline College & -0.098 & $-4.06 * * *$ & -0.094 & $-3.90 * * *$ \\
\hline Obese at 62 & 0.069 & $3.05 * * *$ & 0.066 & $2.95 * * *$ \\
\hline $\max A I M E \_1$ & & & 0.115 & $3.34 * * *$ \\
\hline $\max A I M E \_2$ & & & 0.022 & 0.69 \\
\hline $\max A I M E \_4$ & & & 0.006 & 0.2 \\
\hline $\max A I M E \_5$ & & & -0.008 & -0.25 \\
\hline Log Likelihood & -78 & & -77 & \\
\hline $\mathrm{N}$ & 1,7 & & 1,7 & \\
\hline
\end{tabular}

Source: 1992-2006 HRS; analysis weights for the wave when the individual is age 61/62 are used. Regressions also include Census division fixed effects. *,**, and *** signify significance at the $10 \%, 5 \%$, and $1 \%$ level, respectively. Health limitation in Wave 7 is imputed for those having a health limitation in Wave 6. 
Table 8. Years to Death for Those Observed to Die in the Sample

\begin{tabular}{lc} 
Max AIME Quintile & $\begin{array}{c}\text { Average Years of Life } \\
\text { Remaining at Age 62 }\end{array}$ \\
\hline $1-$ Low & 5.94 \\
2 & 6.30 \\
3 & 7.25 \\
4 & 7.40 \\
$5-$ High & 7.45 \\
\hline Source: $1992-2006$ HRS and authors' calculations; \\
analysis weights for the wave when the individual is age \\
61/62 are used.
\end{tabular}


Figure 1A. Change in the Present Value of Social Security Benefits at age 62 as a Function of Claiming Age, Men

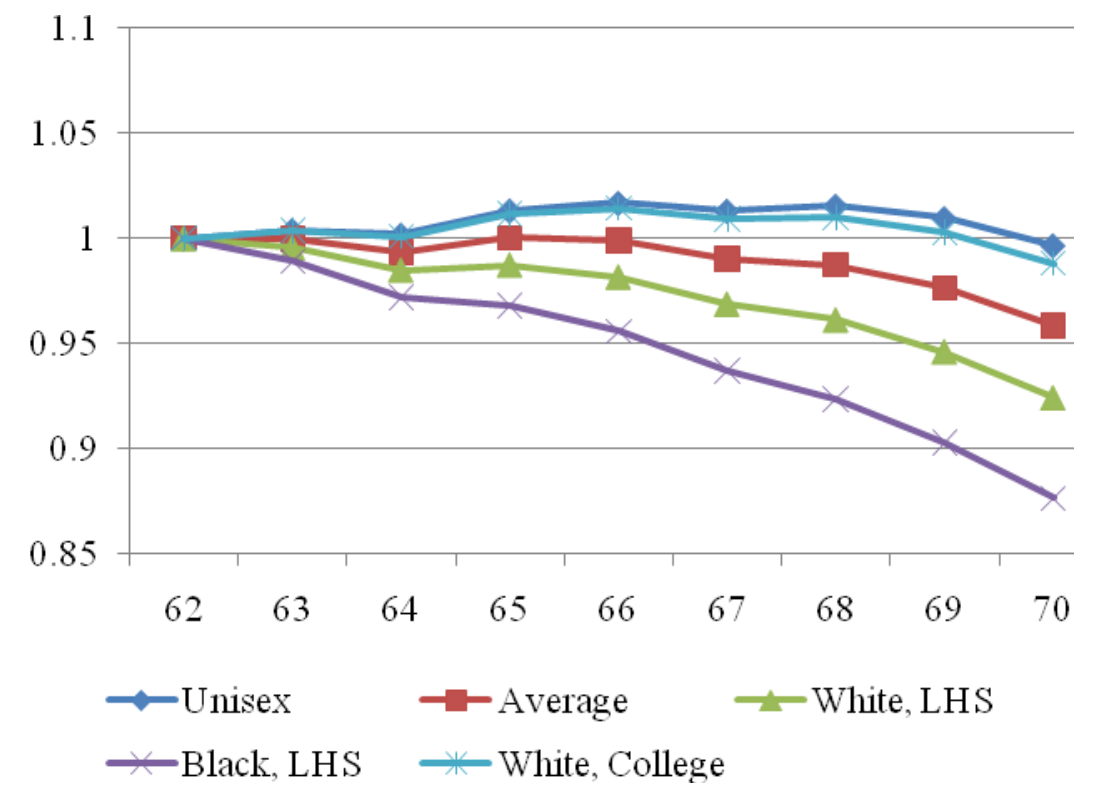

Source: Author's calculations.

Note: Calculated for the cohort born in 1960.

Figure 1B. Change in the Present Value of Social Security Benefits at age 62 as a Function of Claiming Age, Women

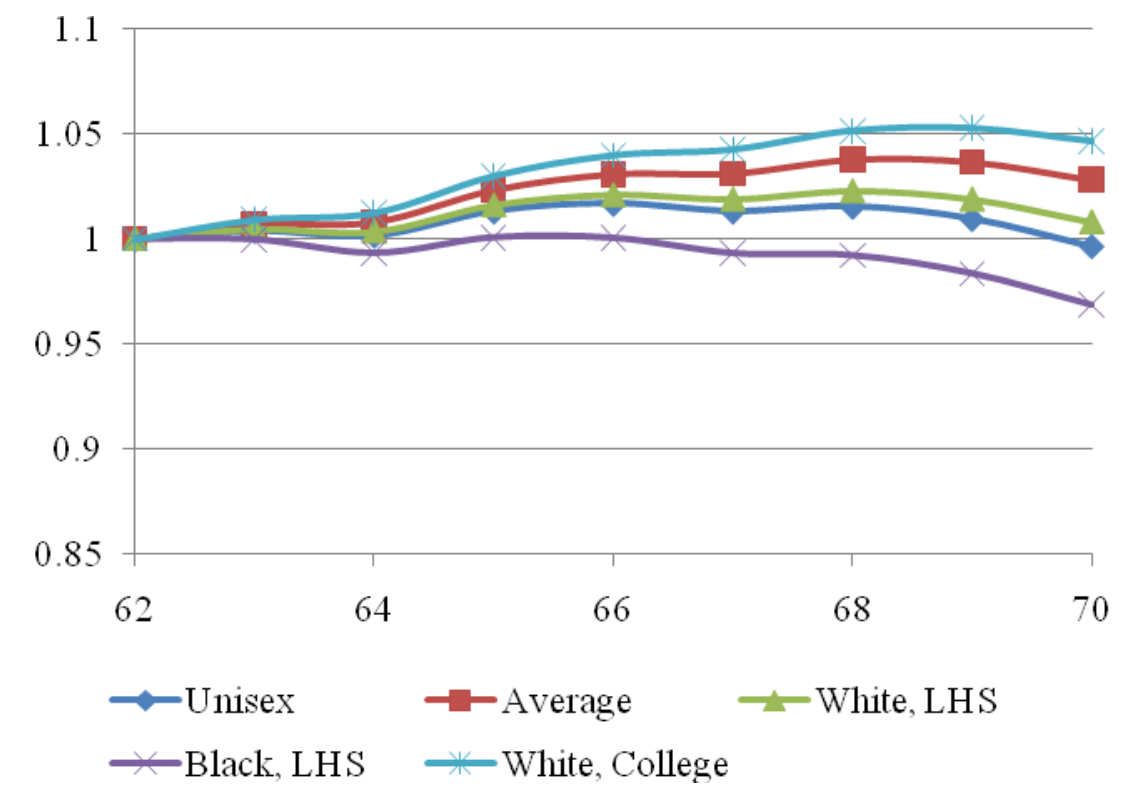

Source: Author's calculations.

Note: Calculated for the cohort born in 1960. 
Figure 2A. Difference in the Present Value of Social Security Benefits as a Function of Claiming Age Relative to a Unisex Individual, Men

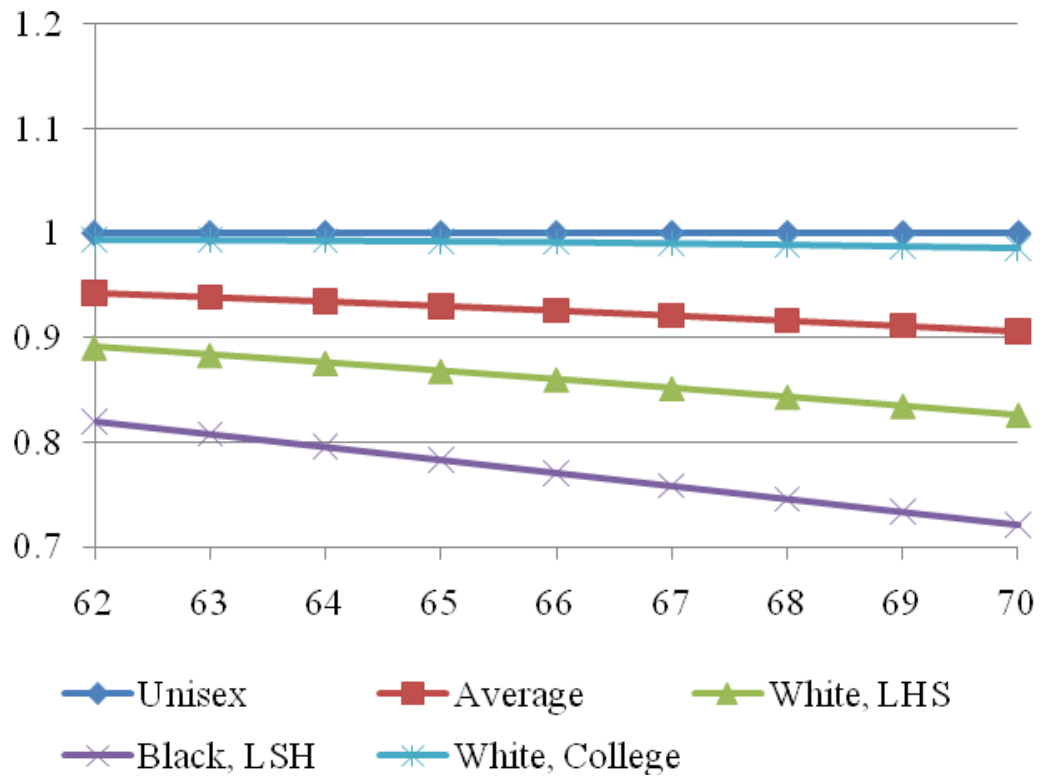

Source: Author's calculations.

Note: Calculated for the cohort born in 1960. We assume the same level of benefits. The only difference is the difference in mortality rates.

Figure 2B. Difference in the Present Value of Social Security Benefits as a Function of Claiming Age Relative to a Unisex Individual, Women

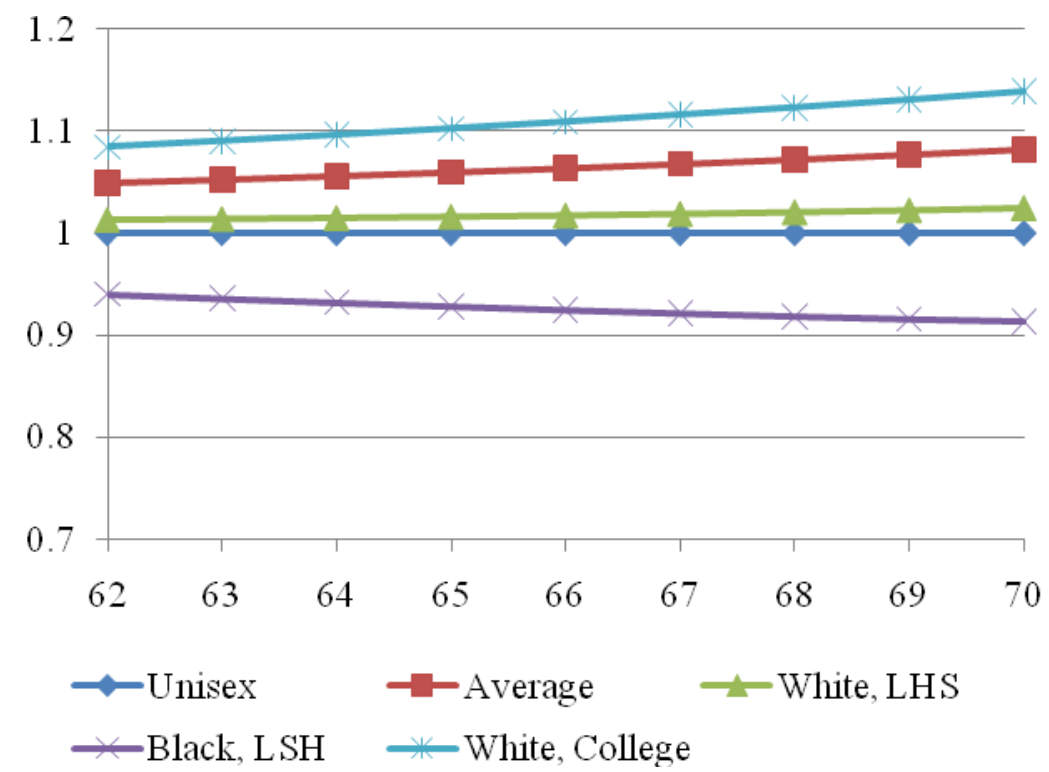

Source: Author's calculations.

Note: Calculated for the cohort born in 1960. We assume the same level of benefits. The only difference is the difference in mortality rates. 
Figure 3. Kaplan-Meier Estimates, by Max AIME Quintile

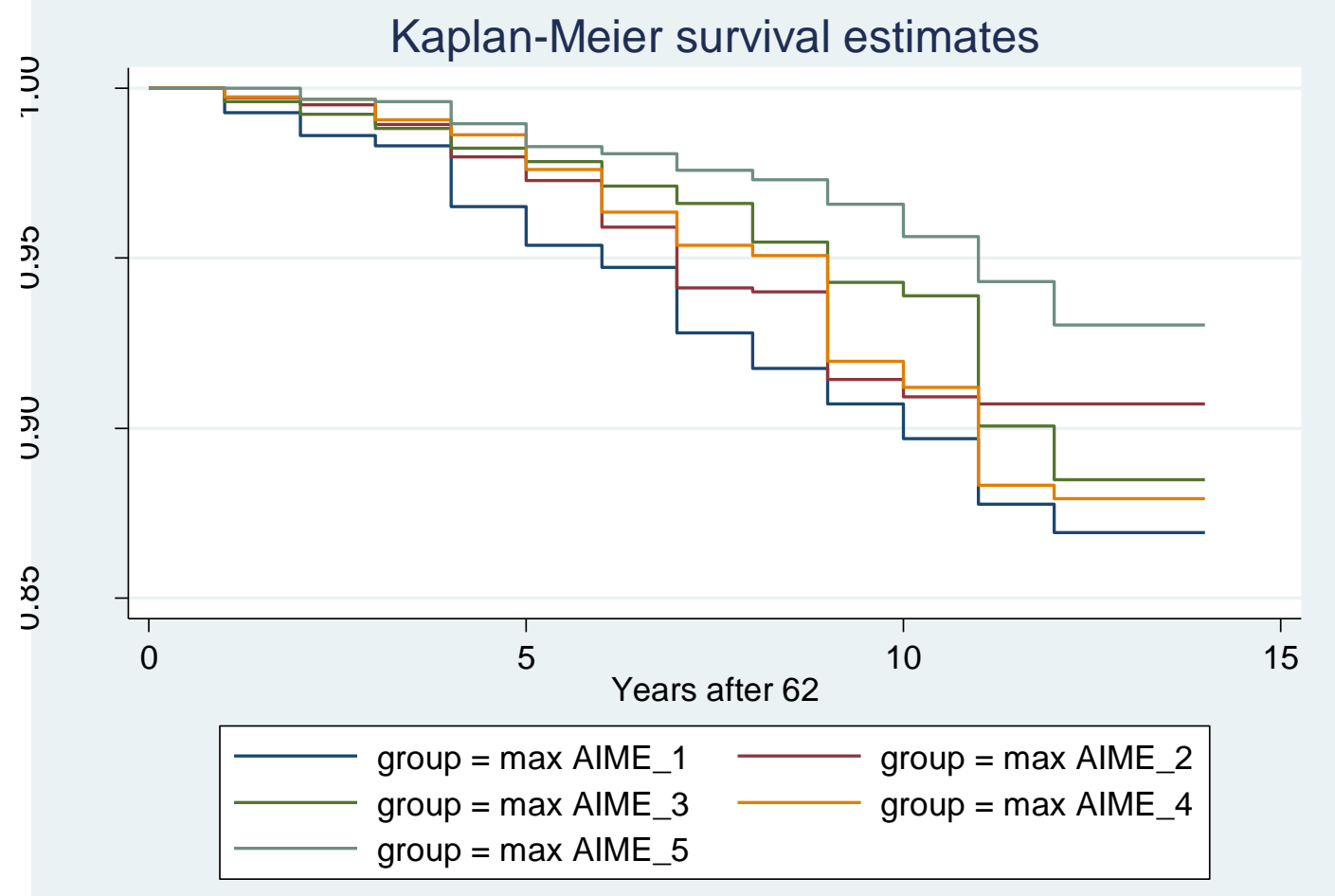

Figure 4. Distribution of Predicted Life Expectancies Based on Hazard Model with Max AIME by Max AIME Quintiles

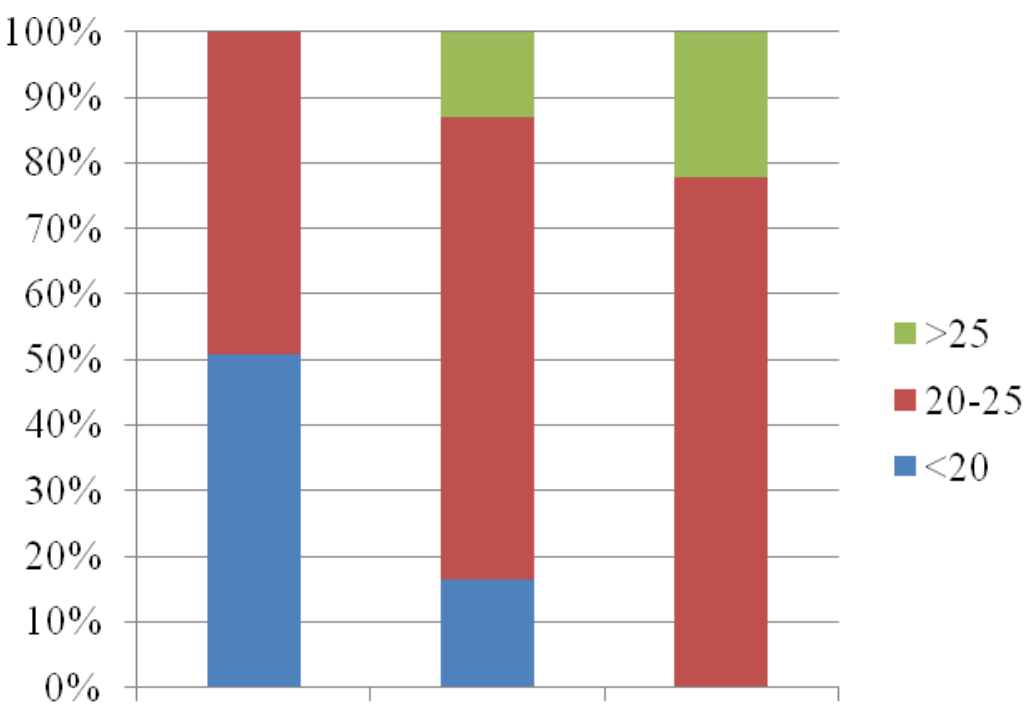

1stQuintile 2-4 Quintiles 5th Quintile

Source: 1992-2006 HRS and authors' calculations; analysis weights for the wave when the individual is age $61 / 62$ are used.

Models include control for quintiles of quarters worked. 
Figure 5. Example of a Flexible FRA based on Ratio of max AIME to National Average Monthly Earnings (NAME)

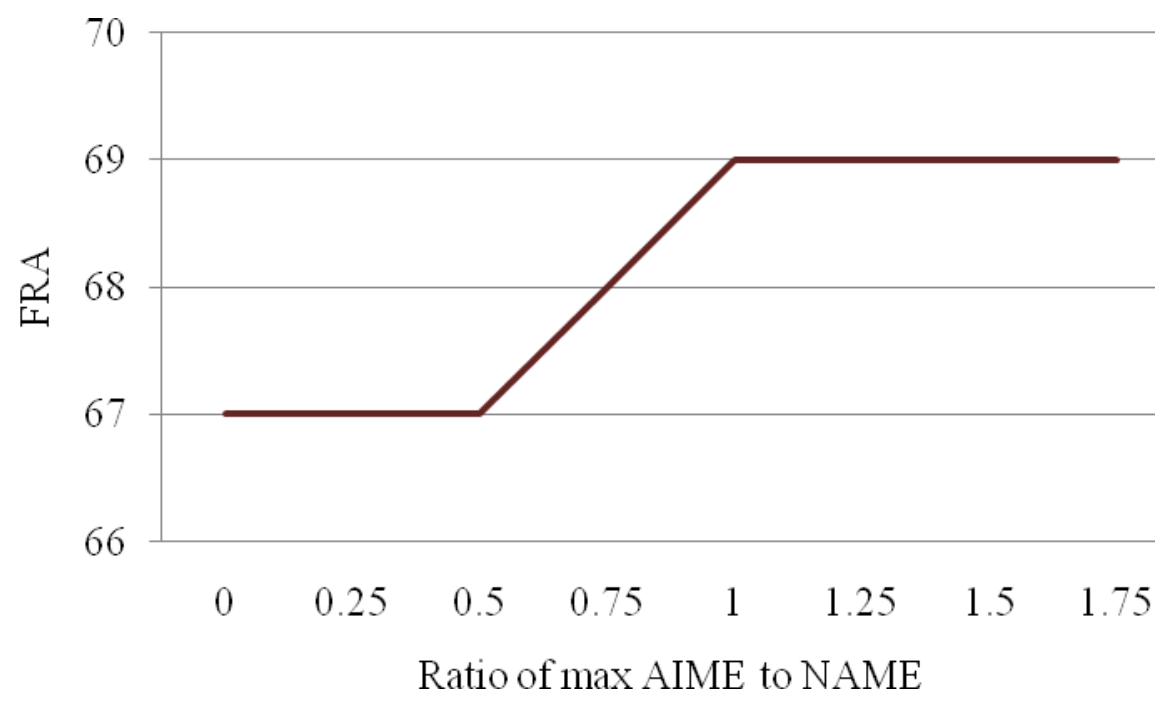

Source: Author's illustration. 


\section{Appendix A: Extra Tables and Figures}

Table A1. Percent of Individuals Whose Max AIME is Own AIME, by Gender and Marital Status

\begin{tabular}{lcc} 
& Married & Unmarried \\
\cline { 2 - 3 } Men & $97 \%$ & $100 \%$ \\
Women & $15 \%$ & $88 \%$ \\
\hline
\end{tabular}

Source: 1992-2006 HRS.

Notes: Analysis weights for the wave when the individual is age 61/62 are used.

Unmarried includes widows and divorces.

Table A2. Summary Statistics for Individuals by Own AIME Quintile

\begin{tabular}{lccccc} 
Own AIME & $\begin{array}{c}\text { \% with } \\
\text { College } \\
\text { Degree }\end{array}$ & $\begin{array}{c}\% \\
\text { White }\end{array}$ & $\begin{array}{c}\text { Fair/Poor } \\
\text { Health at } \\
\text { age } 62\end{array}$ & $\begin{array}{c}\% \\
\text { Married } \\
\text { at age } \\
62\end{array}$ & $\begin{array}{c}\text { Health } \\
\text { Limitation } \\
\text { to Working } \\
\text { at age 62 }\end{array}$ \\
\hline Women & 10 & 93 & 16 & 85 & 24 \\
$1-$ Low & 13 & 88 & 15 & 66 & 19 \\
3 & 16 & 90 & 11 & 63 & 12 \\
4 & 44 & 94 & 1 & 63 & 8 \\
$5-$ High & 61 & 89 & 9 & 28 & 5 \\
Men & & & & & \\
$1-$ Low & 7 & 59 & 21 & 73 & 36 \\
2 & 21 & 77 & 19 & 72 & 22 \\
3 & 14 & 89 & 23 & 75 & 24 \\
4 & 15 & 90 & 15 & 83 & 15 \\
$5-$ High & 33 & 98 & 8 & 91 & 12 \\
\hline
\end{tabular}

Source: 1992-2006 HRS.

Notes: Analysis weights for the wave when the individual is age 61/62 are used. Ranking for own AIME is not separated by gender. 
Table A3. Hazard Model Results with Demographic Characteristics as Explanatory Variables, Conditional on Being Observed Alive at 62

\begin{tabular}{lcc} 
Variable & Hazard Ratio & \multicolumn{1}{c}{ Z-stat } \\
\hline Female & 0.522 & $-3.93^{* * *}$ \\
Non-white & 1.146 & 0.65 \\
Hispanic & 1.294 & 0.66 \\
College & 1.262 & 0.99 \\
Married at 62 & 0.693 & $-2.07 * *$ \\
Fair/poor health at 62 & 2.203 & $4.18^{* * *}$ \\
Wealth at 62 (2006\$) & 1.000 & $-3.19 * * *$ \\
& & \\
$\gamma$ & 0.173 & $8.40^{* * *}$ \\
Pseudo log likelihood & $-2,906,788$ \\
\hline Source: $1992-2006$ HRS; analytical weights for the wave when the individual is age $61 / 62$ are used. *, \\
$* *$, and *** signify significance at the 10\%, 5\%, and 1\% level, respectively.
\end{tabular}

Table A4. Hazard Model Results, Conditional on Being Observed Alive at 62 (Restricted Sample used for Mortality at 70 Analysis)

\begin{tabular}{|c|c|c|c|c|c|c|}
\hline \multirow[b]{2}{*}{ Variable } & \multicolumn{2}{|c|}{1} & \multicolumn{2}{|c|}{2} & \multicolumn{2}{|c|}{3} \\
\hline & $\begin{array}{c}\text { Hazard } \\
\text { Ratio }\end{array}$ & Z-stat & $\begin{array}{c}\text { Hazard } \\
\text { Ratio }\end{array}$ & Z-stat & $\begin{array}{c}\text { Hazard } \\
\text { Ratio }\end{array}$ & Z-stat \\
\hline maxAIME_1 & 1.760 & $2.39 * *$ & & & 1.680 & $2.14 * *$ \\
\hline maxAIME_2 & 1.359 & 1.20 & & & 1.319 & 1.09 \\
\hline $\max A I M E \_4$ & 1.401 & 1.35 & & & 1.482 & 1.59 \\
\hline maxAIME_5 & 0.577 & $-1.84 * *$ & & & 0.664 & -1.37 \\
\hline Max_quarters_1 & & & 2.406 & $4.02 * * *$ & & \\
\hline Max_quarters_2 & & & 1.463 & 1.57 & & \\
\hline Max_quarters_4 & & & 0.437 & $-2.62 * * *$ & & \\
\hline Max_quarters_5 & & & 0.307 & $-3.26 * * *$ & & \\
\hline Own_quarters_1 & & & & & 0.495 & $-2.96 * * *$ \\
\hline Own_quarters_2 & & & & & 0.894 & -0.51 \\
\hline Own_quarters_4 & & & & & 0.838 & -0.76 \\
\hline Own_quarters_5 & & & & & 0.263 & $-4.1 * * *$ \\
\hline$\gamma$ & 0.094 & $4.24 * * *$ & 0.089 & $4.08 * * *$ & 0.093 & $4.22 * * *$ \\
\hline Pseudo log likelihood & $-2,856,643$ & & $-2,768,843$ & & $-2,814,241$ & \\
\hline
\end{tabular}

Source: 1992-2006 HRS; analytical weights for the wave when the individual is age 61/62 are used. Reference category is the middle quintile maxAIME_3. *,**, and *** signify significance at the $10 \%, 5 \%$, and $1 \%$ level, respectively. 
Table A5. The Mean Values for the Ratio of AIME to National Average Monthly Earnings (NAME) and AIME, HRS

\begin{tabular}{lcc}
$\begin{array}{l}\text { Max AIME } \\
\text { Quartile }\end{array}$ & $\begin{array}{c}\text { Ratio of AIME to } \\
\text { NAE }\end{array}$ & AIME \\
\cline { 1 - 1 } $1-$ Low & 0.49 & $\$ 12,695$ \\
2 & 1.07 & 27,662 \\
3 & 1.50 & 37,666 \\
4 & 1.82 & 44,579 \\
$5-$ High & 2.22 & 50,570 \\
\hline
\end{tabular}

Source: 1992-2006 HRS and authors' calculations.

Table A6. Labor Force Participation at Various Ages, by Max AIME Quintile

\begin{tabular}{lccc} 
Max AIME Quintile & Age 62 & Age 65 & Age 67 \\
\hline $1-$ Low & $40 \%$ & $25 \%$ & $22 \%$ \\
2 & $51 \%$ & $24 \%$ & $22 \%$ \\
3 & $41 \%$ & $24 \%$ & $18 \%$ \\
4 & $37 \%$ & $17 \%$ & $14 \%$ \\
$5-$ High & $43 \%$ & $18 \%$ & $15 \%$ \\
\hline
\end{tabular}

Source: 1992-2006 HRS.

Notes: Labor force participation as defined in the RAND dataset version $i$, working part-time or fulltime. Unweighted. Sample is that used in Section $2 B$. 
Figure A1. Change in the Present Value of Social Security Benefits at age 62 as a Function of Claiming Age, Couple

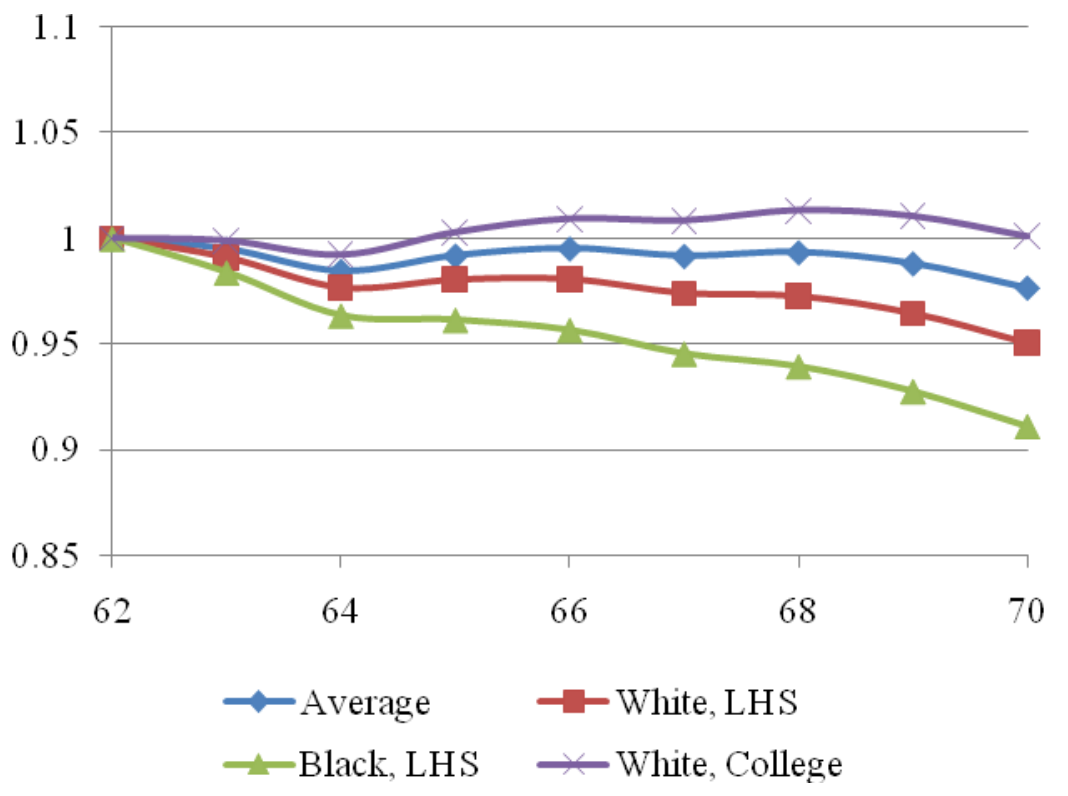

Source: Author's calculations.

Note: Calculated for the cohort born in 1960. Assume that both spouses were born in the same year.

Figure A2. Probability of Death by Age, Conditional on Being Alive One Year Earlier

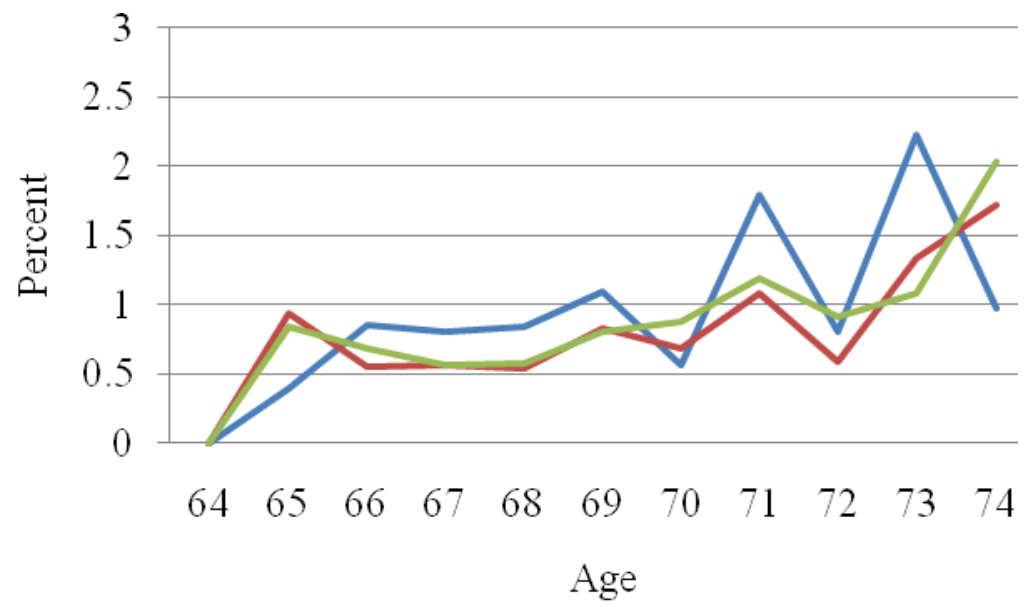

- Observed

— Predicted by Max AIME model

- Predicted by Demographic Characteristics Model

Source: 1992-2006 HRS.

Notes: Analysis weights for the wave when the individual is age 61/62 are used. Results not broken down by sex because of small sample sizes. See Table 4 for the results of hazard model. 


\section{Appendix B: Hazard Model Results with Altered Sample}

The sample used to generate the hazard model results in the main body of the paper drops those people with missing earnings data due to an early permissions year. For example, an HRS cohort member who is aged 52 in 1992 gives his permission for linked Social Security records, but does not renew it in 2004. Therefore his earnings record is incomplete, and his AIME appears artificially low because of missing years of work. To test the effect on our results of dropping these individuals from the sample, we replace missing data from those with early permissions years with the last observed year of earnings, until the individual is age 65 or dies. ${ }^{30}$ A hazard model is then run on this larger sample; the results are presented in Table B1. These results mirror closely those in reported in Table 4. Most importantly, the high mortality of the bottom max AIME group is replicated here.

Table B1. Hazard Model Results, Conditional on Being Observed Alive at 62 (AIME Replaced for Early Permissions Individuals)

Variable

maxAIME_1

maxAIME_2

maxAIME_4

$\max$ AIME_5

Own_quarters_1

Own_quarters_2

Own_quarters_4

Own_quarters_5

$\Gamma$

Pseudo log likelihood

Source: 1992-2006 HRS; analytical weights for the wave when the individual is age 61/62 are used. Reference category is the middle quintile maxAIME_3. * ${ }^{* *}$, and $* * *$ signify significance at the $10 \%$, $5 \%$, and $1 \%$ level, respectively.

\footnotetext{
${ }^{30}$ An alternative strategy not explored here is to use self-reported earnings data. We do not do this since earnings data is recorded every two years in the HRS.
} 


\section{RECENT WORKING PAPERS FROM THE}

\section{CENTER FOR RETIREMENT RESEARCH AT BOSTON COLLEGE}

Work and Retirement Patterns for the G.I. Generation, Silent Generation, and Early Boomers: Thirty Years of Change

Richard W. Johnson, Barbara A. Butrica, and Corina Mommaerts, July 2010

Spousal Health Shocks and The Timing Of The Retirement Decision in the Face of Forward-Looking Financial Incentives

Courtney Harold Van Houtven and Norma B. Coe, June 2010

Incorporating Employee Heterogenity Into Default Rules for Retirement Plan Selection

Gopi Shah Godi and Colleen Flaherty Manchester, May 2010

Accurately Measuring Health Over the Life Course

Fabian Lange and Doug McKee, May 2010

Getting to the Top of Mind: How Reminders Increase Saving

Dean Karlan, Margaret McConnell, Sendhil Mullainathan, and Jonathan Zinman, April 2010

The Shrinking Tax Preference for Pension Savings: An Analysis of Income Tax Changes, 1985-2007

Gary Burtless and Eric Toder, March 2010

Social Security, Benefit Claiming and Labor Force Participation: A Quantitative General Equilibrium Approach

Selahattin Imrohoroğlu and Sagiri Kitao, March 2010

How Much Is Enough? The Distribution of Lifetime Health Care Costs

Anthony Webb and Natalia Zhivan, February 2010

Impact of Immigration on the Distribution of American Well-Being

Gary Burtless, December 2009

Actual and Anticipated Inheritance Receipts

Norma B. Coe and Anthony Webb, December 2009

Will Automatic Enrollment Reduce Employer Contributions to 401(k) Plans

Mauricio Soto and Barbara A. Butrica, December 2009

All working papers are available on the Center for Retirement Research website

(http://crr.bc.edu) and can be requested by e-mail (crr@bc.edu) or phone (617-552-1762). 